\title{
COMPOSITES FROM NATURAL FIBRES
}

\author{
A.O. Abdul Salam Sait ${ }^{1}$, Venkatraman Subramaniam ${ }^{2}$ \\ ${ }^{1}$ Associate Professor, National Institute of Fashion Technology, Chennai-113 \\ ${ }^{2}$ Professor, Jaya Engineering College, Chennai-602024
}

\begin{abstract}
It is an incontrovertible fact that currently a number of natural fibres such as jute, flax bamboo coir and okra are being considered as suitable candidates for fibre reinforcement material in composites following chemical modification. Some of the fibres show hydrophobic behaviour following chemical treatments which makes them ideal for use in composites. Although a great deal of works has been done on the application of natural fibres by many research workers, only a few aspects of work have been reported and there are many questions to be answered. This paper addresses some of the issues connected with composites which are produced from natural fibres. In order to have information on the structure properties and their interrelationships, a considerable amount of work has been reported but some more work is desirable. Also, data on their properties following chemical modification are required.
\end{abstract}

Keywords: Natural Fibres, bamboo fibres, flax fibres

\section{INTRODUCTION}

It is an incontrovertible fact that currently a number of natural fibres such as jute, flax bamboo coir and okra are being considered as suitable candidates for fibre reinforcement material in composites following chemical modification. Some of the fibres show hydrophobic behaviour following chemical treatments which makes them ideal for use in composites. Although a great deal of works has been done on the application of natural fibres by many research workers, only a few aspects of work have been reported and there are many questions to be answered. This paper addresses some of the issues connected with composites which are produced from natural fibres. In order to have information on the structure properties and their interrelationships, a considerable amount of work has been reported but some more work is desirable. Also, data on their properties following chemical modification are required.

\section{RESEARCH WORK DONE}

Zafeiro Poulous, Dijon and Baillie (2007) have reported extensive work on the effect of treatments on the tensile strength of flax fibres. Flax fibres were subjected to acetylation and stearation. They were treated for different periods and tested at gauge lengths of 5, 8 and $10 \mathrm{~mm}$. SEM analysis of fractured surfaces was also done and detailed statistical analysis was performed by assuming the distribution to be normal or gaussian. Thus their study focused on the effect of surface treatments upon the tensile strength of flax fibres. It was found that the treatments did not significantly change the flax fibre tensile strength. SEM examination of the fractured surfaces revealed that acetylated fibres exhibit a different mode of failure from the other fibres. They have not done characterization of treatment fibres by XRD and FTIR.

What is most significant in their research is the analysis of the data by Weibull modeling. Two different methods (the linear regression and the maximum likelihood) were employed in order to estimate the Weibull modulus (m) and the Weibull characteristic strength $\left(\sigma_{\mathrm{o}}\right)$. The two methods yielded similar values for the Weibull modulus (m) and the Weibull characteristic strength $\left(\sigma_{\mathrm{o}}\right)$. It was found that the surface treatments did not significantly change the tensile strength of flax fibres. They have also critically analysed the computation of $\mathrm{m}$ and $\sigma_{\mathrm{o}}$ by using four estimators. However, the Kolmogorav and Smirnov test has not been performed to test the validity of Weibull distribution. Bergman (1984) studied the statistical properties of the four estimator through a Monte Carlo simulation and showed that majority of the estimators gave conservative estimations of the Weibull modulus i.e., lower values than the real value. However, Trustrum and Jayatilaka (1979) have reported that for sample sizes less than 40, maximum likelihood best results of $\mathrm{m}$ and $\sigma_{\mathrm{o}}$ were obtained and for sample sizes which are above 40, the estimate with the smallest standard error is obtained by the least squares estimate.

On jute fibres, Roy et al (2012), Saha et al (2010), Defoirdt et al (2010), Xia et al (2002) and Sinha et al (2008) have dealt with the modification of jute fibres. Zhang, Pan and Wang (1992) found very good improvement in the accuracy of predicted values by considering the diameter variation using Weibull distribution. The same methodology was followed by two research workers, namely Xia et al (2009) for jute and Sia et al (2014) for treated oil palm fibres. This exponent was 
suggested by Watson and Smith (1985) and Gutans and Tamuzh (1984) to narrow the differences between experimental and predicted values of Weibull modulus. This modified Weibull modulus was found to be more accurate for prediction of mechanical properties. Although Roy et al (2012) provide tensile strength data on jute fibres following treatment by low concentration of alkali, the values of untreated jute fibres are not given. Igar Maria De Rosa et al (2010) have given the tensile properties of New Zealand flax (phormium tenax) technical fibres which are to be used as potential reinforcement in polymer matrix composites. They have carried out single fibre tensile tests at three gauge lengths to assess the effect of gauge length on tensile strength and Young's modulus. Weibull distribution was used for analyzing the results. The morphology, diameter and fracture modes of P. tenax fibres were also characterized through optical and scanning electron microscopy.

Shao et al (2013) and Das et al (2006) have dealt with the bamboo fibres, the former dealing with scaling analysis of the tensile strength of bamboo fibres using Weibull statistics and the latter with the influence of alkali treatment on the fine structure and morphology of bamboo fibres. Shao et al (2013) have demonstrated that the two parameter Weibull model can be used for predicting the strength distribution of fibres of longer gauge lengths.

Das et al (2006) have studied the influence of alkali treatment on the fine structure and morphology of bamboo fibres. Structural parameters such as crystallinity, orientation angle, degree of crystallinity, and crystallinity index were studied. Andersons et al (2008) have studied the strength distribution of elementary flax fibres due to mechanical defects. Virk (2010) has characterized the physical properties using digital images. It was found that the true fibre area followed a lognormal distribution. Tensile tests were carried out at ten different gauge lengths between $6 \mathrm{~mm}$ and $300 \mathrm{~mm}$ and the Young's modulus strain to failure and ultimate tensile strengths were determined individually. A strong correlation was found between the fibre strength/fracture strain and fibre gauge length. As expected, it was found that as the gauge length increased, the fibre strength/fracture strain dropped. The fibre failure (strength/strain) was modeled using Weibull distribution and three statistical models were developed to relate the fibre strength/fracture strain to the fibre gauge length. An examination of the data revealed that the coefficient of variation $(\mathrm{CoV})$ for failure strain was consistently lower than that of the $\mathrm{CoV}$ for fracture stress (strength) as the failure strain was influenced by the fibre, cross section. Hence failure strain is the more consistent failure criterion and it was recommended to use failure strain as the key design criterion for natural fibre composites in order to improve reliability in the design of these materials. Also, the elastic modulus using fibre angle and length distribution was modeled using rule of mixtures. Improved prediction in tensile modulus due to the incorporation of fibre area correction factor was noticed. Basalt fibres were also studied in detail by Militky and Kovacic (2011), Dirikolu et al (2002) have conducted a statistical analysis of composite materials using Weibull distribution. The reliability of the materials was also1 studied.

\section{CONCLUSIONS}

Thus a considerable amount of work has been done on natural fibres for use in composites. Further work is required on the blends of natural fibres silk and their characterization following chemical modification. This is a fertile area of research, and a considerable amount of work is warranted.

\section{REFERENCES}

[1] Andersons, J., Sparnins, E., Joffe, R. and Wallstrom, L., 2005, Strength distribution of elementary flax fibres. Compos. Sci. Technol., 65, 693-702.

[2] Bergman, B. 1984, Journal of Material Science Letters, 3,689 .

[3] Das, M. and Chakraborty, D., 2006, Influence of alkali treatment on the fine structure and morphology of bamboo fibres. Journal of Applied Polymer Sci., Vol.102, 5050-5056.

[4] Defoirdt, N., Biswas, S., Vriese, L.D., Tran, L.Q.N., Acker, J.V., Ahsan, Q., Gorbatikh, L., Vuure, A.V., Verpoest, I. 2010, Assessment of the tensile properties of coir, bamboo and jute fibre, Composites, Part A, 41, 588-595.

[5] Dirikolu, M., Aktas, A., Birgoren, B., 2002, Statistical Analysis of fracture strength of composite materials using Weibull distribution, Turkish. J. Eng. Env., Sci., 26, 45-48.

[6] Gutans, J.A. and Tamuzh, V.P. 1984, Scale effect of the Weibull distribution of fibre strength, Mechanical Composite Materials, Vol.6, 1107-1109.

[7] Militky, J. and Kovacic, V. 2011, Selected topics of textile and material Science, TUL FT Liberee.

[8] Pickering, K.L., Murray, T.L., 1999, Weak link scaling analysis of high-strength carbon fibre composites, Part A, 1017-1027.

[9] Ray, D., Sarkar, B.K., 2001, Characterization of alkalitreated jute fibres for physical and mechanical properties, J. Appl. Polym. Sci., 80, 1013-1020.

[10] Rosa, I.M.D., Kenny, J.M., Puglia, D., Santulli, C., Sarasini, F., 2010, Morphological, thermal and mechanical characterization of Okra (Abelmoschus esculentus) fibres as potential reinforcement in polymer composites, Compos. Sci. Technol., Vol.70, No.1, 116122.

[11] Roy, A., Chakraborty, S., Kundu, S.P., Basak, R.K., Majumdar, B., Adhikari, B., 2012, Improvement in mechanical properties of jute fibres through mild alkali treatment as demonstrated by utilization of the Weibull model, Bioresource Technology, 107, 222-228. 
[12] Saha, P., Manna, S., Roy Chowdhury Sen, R., Roy, D., Adhikari, B., 2010, Enhancement of tensile strength of lingo cellulosic jute fibres by alkali-steam treatment, Bioresource. Technol. 101, 3182-3187.

[13] Shao, J., Wang, F., Li Lu, Zhang, J. 2013, Scaling analysis of the tensile strength of bamboo fibres using Weibull statistics, Advances in Materials Science and Engineering, Vol.1, 1-6.

[14] Sia, C., Nakai, N., Shiozawa, D., Ohtani, H. 2014, Statistical analysis of the tensile strength of treated palm fibre by utilization by utilization of Weibull Distribution model, Open Journal of Composite Materials, 4, 72-77.

[15] Sinha, S., Rout, S.K., 2008, Influence of fibre-surface treatment on structural, thermal and mechanical properties of jute, Journal of Material Science, 43, 2590-2601.

[16] Trustrum, K., Jayatilaka, D.S. 1979, on estimating the Weibull modulus for a brittle material. Journal of Materials Science, 14, 1080-1084.

[17] Virk, A.S., 2010, Numerical models for natural fibre composites with stochastic properties, Ph.D., Thesis, School of Marine Science and Engineering, University of Plymouth, UK.

[18] Watson, A.S. and Smith, R.L. 1985, An examination of statistical theories for fibrous materials in the light of experimental data, Journal of Material Science, Vol.20, No.9, 3260-3270.

[19] Wu, H.F. and Netravali, A.N. 1992, Journal of Materials Science, Vol.27, No.12, 3318-3324.

[20] Xia, Z.P., Yu, J.Y., Cheng, L.D., Liu, L.F. and Wang, W.M. 2009, Study on the breaking strength of jute fibres using modified Weibull distribution, Composites Part A, 40, 54-59.

[21] Zafeiropoulous, N.E. and Baillie, 2007, Part, Composites, Part A, 38, 629-

[22] Zafeiropoulous, N.E., Dijon and Baillie, 2007, Part, Composites Part A, 38, 62-628.

[23] Zhang, Y., Wang, X., Pan, N. and Postle, R., 1992, Weibull analysis of strength length relationships in single Nicalonsic fibres, Journal of Materials Sciences, Vol.37, No.7, 1401-1406. 